Published in final edited form as:

Environ Sci Technol Lett. 2019 December 10; 6(12): 696-701. doi:10.1021/acs.estlett.9b00599.

\title{
Indoor versus Outdoor Air Quality during Wildfires
}

\author{
K.P. Messier ${ }^{1}$, L.G. Tidwell ${ }^{1}$, C.C. Ghetu ${ }^{1}$, D. Rohlman ${ }^{3}$, R.P. Scott ${ }^{1}$, L.M. Bramer ${ }^{4}$, H.M. \\ Dixon $^{1}$, K.M. Waters ${ }^{1,2}$, K.A. Anderson ${ }^{*}, 1$ \\ ${ }^{1}$ Department of Environmental and Molecular Toxicology, Oregon State University, Corvallis, \\ Oregon, 97331, United States of America \\ ${ }^{2}$ Biological Sciences Division, Pacific Northwest National Laboratory, Richland, Washington, \\ 99352, United States of America \\ ${ }^{3}$ College of Public Health and Human Sciences, Oregon State University, Corvallis, Oregon, \\ 97331, United States of America \\ ${ }^{4}$ Computational Analytics Division, Pacific Northwest National Laboratory, Richland, 99352 , \\ Washington, United States of America
}

\begin{abstract}
The human behavioral modification recommendations during wildfire events are based on particulate matter and may be confounded by the potential risks of gas-phase pollutants such as polycyclic aromatic hydrocarbons (PAHs). Moreover, the majority of adults spend over 90 percent of their time indoors where there is an increased concern of indoor air quality during wildfire events. We address these timely concerns by evaluating paired indoor and outdoor PAH concentrations in residential locations and their relationship with satellite model-based categorization of wildfire smoke intensity. Low-density polyethylene passive air samplers were deployed at six urban sites for 1 week in Eugene, Oregon with matched indoor and outdoor samples and $24 \mathrm{~h}$ time resolution. Samples were then quantitatively analyzed for $63 \mathrm{PAH}$ concentrations using gas-chromatography-tandem mass spectrometry. A probabilistic principal components analysis was used to reduce all 63 PAHs into an aggregate measure. Linear regression of the first principal component against indoor versus outdoor shows that indoor gas-phase PAH concentrations are consistently equal to or greater than outdoor concentrations. Regression against a satellite-based model for wildfire smoke shows that outdoor, but not indoor gas-phase PAH concentrations are likely associated with wildfire events. These results point toward the need to include gas-phase pollutants such as PAHs in air pollution risk assessment.
\end{abstract}

\section{Graphical Abstract}

\footnotetext{
"Corresponding author: Kim A. Anderson, Oregon State University, Department of Environmental and Molecular Toxicology, 1007 Agricultural and Life Sciences Building, Corvallis, Oregon 97331, USA, Telephone: (541) 737-8501, Fax: (541) 737-0497, kim.anderson@oregonstate.edu.

Supporting Information:

Supporting information is available free of charge on the ACS Publications website. SI contains monitoring site descriptions, PAH property table, and a supporting figure.
} 


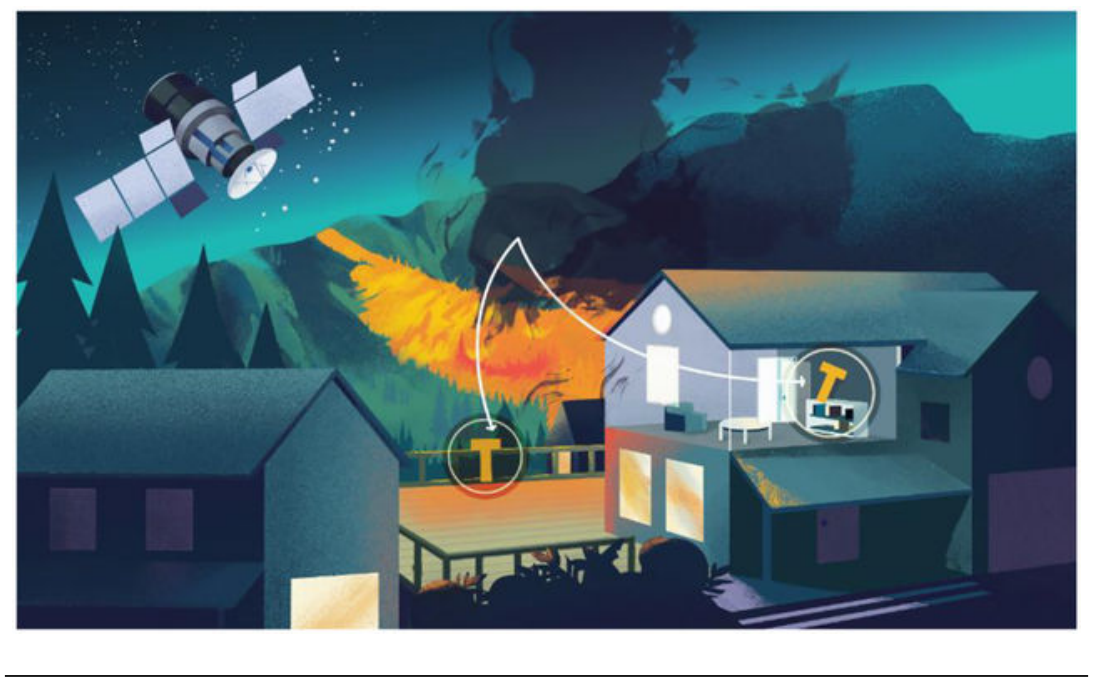

\section{Introduction}

Wildfire events result in definitive economic ${ }^{1,2}$ and human disease ${ }^{3,4}$ burdens. These will be increasingly felt worldwide, with many areas expected to experience intensification and expansion of wildfires globally. ${ }^{5}$ Climate-fire relationship modeling has predicted significant spatial variability in wildfire risk in the western United States under climate change scenarios, with many regions likely to experience increased wildfire severity depending on ecological factors such as antecedent rainfall and vegetation type. ${ }^{6}$ Among the areas with increased severity, forested regions of California, United States, experienced a 5-fold increase in summer wildfire extent from 1972-2018 due to aridity caused by warming. ${ }^{7}$ Additionally, rapid development along the wildland-urban interface has been shown to increase economic and mortality risk of wildfires, with the effects possibly compounded by climate change. ${ }^{8}$

The primary recommendation for behavioral modification during wildfire events is to stay indoors. ${ }^{9,10}$ This recommendation is based entirely on epidemiologic evidence of particulate matter (or categorical smoky vs. non-smoky days) exposure from wildfire events and many health outcomes (e.g., mortality, respiratory morbidity, asthma, etc.). ${ }^{4}$ However, it is known that wildfire smoke is a complex mixture composed of particulate and gas phase chemicals including polycyclic aromatic hydrocarbons (PAHs). Delgado-Saborit et al. found 16 particle-phase PAHs to be lower indoors than outdoors, with the exception of environmental tobacco smoke or wood-burning stoves source locations, ${ }^{11}$ but made no measurements of gas-phase PAH. In regards to PAH mixtures and health outcomes, multiple studies have found gas-phase PAHs may contribute more to carcinogenic toxicity than particle-phase PAHs. ${ }^{12,13}$ Recently, Samburova et al. ${ }^{14}$ analyzed the results of 13 PAH studies and found that only looking at particulate matter can significantly underestimate carcinogenic potency of PAH mixtures and Ramírez et al. ${ }^{12}$ found gas-phase PAHs contributed up to $86 \%$ of total PAH carcinogenic toxicity.

The majority of adults spend over $90 \%$ of their time indoors. ${ }^{15-17}$ Moreover, there is an increased concern of indoor air quality, including PAHs of outdoor origin ${ }^{17}$, and adverse 
health outcomes during wildfire events. ${ }^{18}$ Therefore, quantifying the exposure potential to gas-phase PAHs indoors and outdoors is important. Additionally, understanding the distributions of gas-phase PAHs in relation to wildfire events is imperative for improving public health recommendations. Here, we quantitatively compared paired indoor and outdoor PAH concentrations in urban locations. We assessed the relationship between the PAH concentrations and satellite model-based categorization of wildfire smoke intensity. We used low-density polyethylene (LDPE) passive samplers ${ }^{19}$ that are capable of passively sequestering thousands of gas-phase organic pollutants in a biomimetic manner. The results will provide evidence towards developing more complete public health recommendations for indoor air quality and wildfire events.

\section{Materials and Methods}

\subsection{Study Domain and Design}

This study was performed from 7-August-2018 to 13-August-2018, in Eugene, Oregon, United States (Figure 1). Eugene is a metropolitan area (2010 population: 156,185) in Lane County, Oregon, situated in the southern end of the Willamette Valley, between the Oregon coastal mountain range to the west and the larger Cascade Range to the east. Lane County and the surrounding area is a combination of forested and agricultural land. Climate records have shown that western North America has a variable history of wildland fires over several millenia ${ }^{20}$ and is likely to see increased wildfire prevalence due to anthropogenic warming of the climate. ${ }^{5}$

Stationary passive LDPE air samplers were deployed at six locations across Eugene. At each site, samplers were placed in a room inside and outside the building. Sampling took place in $24 \mathrm{~h}$ intervals for a total of seven days. Indoor locations within the building were located away from obvious PAH sources such as kitchens (SI). One outdoor site was chosen for replicate measurement $(n=3)$ collection. One site (Site F) lacked samples for indoor days 5 and 6 due to logistical constraints during the weekend. All other sites had complete sampling. The study location and time was chosen because air quality during the summer months is commonly impacted by wildfires in the North America.

Details of the LDPE sampling setup are described in detail elsewhere. ${ }^{21}$ Briefly, samplers consist of five LDPE strips threaded tautly in open-air metal cages positioned between the floor and the adult breathing-zone height. At five of the six sites LDPE was deployed daily by trained volunteers. A major benefit of the passive samplers is the ease for citizen scientists to participate and allows for multiple sites to be collected simultaneously.

\subsection{Laboratory Analyses}

Details about chemistry analyses are available elsewhere. ${ }^{21}$ Briefly, LDPE is prepared for field deployment through hexane cleaning and infusion with performance reference compounds (PRCs). Post deployment, LDPE is solvent rinsed with reagent grade isopropanol, spiked with deuterated PAH extraction surrogates, hexane extracted, concentrated to $1 \mathrm{~mL}$, and stored at $-20^{\circ} \mathrm{C}$ until analysis. Field and laboratory blanks were also analyzed. 
LDPE extracts were quantitatively analyzed for 63 PAHs using a PAH select column on an Agilent 7890 gas chromatograph interfaced with an Agilent 7000 triple quadrupole mass spectrometer. ${ }^{22}$ The method was recently improved from the quantification of 62 to 63 individual PAHs. Results were validated using at least six points of calibration with correlations of at least 0.99 . The $5^{\text {th }}$ and $95^{\text {th }}$ percentile of the limits of detection (LOD) were $0.003(1.05 \mathrm{e}-5)$ and $0.21(1.3 \mathrm{e}-3) \mathrm{ng} / \mathrm{m}^{3}\left(\mathrm{nmol}-\mathrm{m}^{-3}\right)$, respectively. LODs are detailed in the SI.

\subsection{Statistical Analyses}

Prior to statistical analysis, air concentrations $\left(n g-\mathrm{m}^{-3}\right)$ were calculated from instrument concentrations (pg/ $\mu \mathrm{L}$ ) using PRCs. ${ }^{23}$ These calculations, described in detail in Paulik et.al. ${ }^{21}$, incorporate deployment time, initial concentration, and a temperature-corrected samplerair partition coefficient, $K_{S a(T)}{ }^{24}$ The air concentrations were converted to nanomols-percubic-meter $\left(\mathrm{nmol}-\mathrm{m}^{-3}\right)$ in order to equitably compare between PAHs of varying molecular weights.

Trends for individual PAHs were analyzed between indoor and outdoor environments through exploratory visual analysis. To address our primary objectives, we performed a dimension reduction that results in a single variable accounting for the distributions of all PAHs with at least one observation above the LOD. We implemented probabilistic principal components analysis (PPCA), which rigorously accounts for PAHs observed below the limit of detection. ${ }^{25,26}$ First, we regressed the first principal component against a binary indicator variable for indoor and outdoor locations plus a within site matching categorical covariate intended to reduce the standard error of covariate of interest (i.e. indoor/outdoor). Second, we joined the first principal component with a National Oceanic and Atmospheric Association (NOAA) satellite-based model for wildfire smoke called the Hazard Mapping System (HMS). ${ }^{27}$ The HMS provides a coarse-spatially and daily-temporally resolved categorical quantification of wildfire impacts developed from the combination of satellite sensors, machine learning algorithms, and visual inspection from highly-trained personnel. ${ }^{28}$ We reduced the lowest category, representing low-levels $\left(5 \mu \mathrm{g}-\mathrm{m}^{-3}\right)$ of wildfire-originated smoke and the null (no wildfire smoke), to be the baseline category. The next categories represent medium $\left(16 \mu \mathrm{g}-\mathrm{m}^{-3}\right)$ and high $\left(27 \mu \mathrm{g}-\mathrm{m}^{-3}\right)$ levels of wildfire smoke. Separate models for the indoor and outdoor values of the first principal component are regressed against the HMS categorical variables.

\section{Results and Discussion}

Figure 2 shows the limit of detection (LOD), median of samples above LOD, and the maximum air concentrations $\left(\mathrm{nmol}-\mathrm{m}^{-3}\right)$ for each PAH in which at least one sample was observed above detection. Two primary trends emerge: First, indoor median and maximum concentrations are equal to or greater than outdoor concentrations for the majority of individual PAHs. Second, the air concentration increases with decreasing $\log \mathrm{K}_{\mathrm{oa}}$, the octanol-air partition coefficient. $\log \mathrm{K}_{\mathrm{oa}}$ values were obtained from the USEPA Estimation Programs Interface Suite. ${ }^{29}$ 
In total, 31 out of the 63 PAHs measured were detected in at least one sample, with more detects observed in indoor samples compared to outdoor (logistic regression of detects on indoor/outdoor, $\mathrm{p}=0.0004)$. The majority of detected PAHs were low to mid molecular weight PAHs (approximately 128 to $200 \mathrm{~g}-\mathrm{mol}^{-1}$ ). The highest molecular weight PAH detected was retene $\left(234.3 \mathrm{~g}-\mathrm{mol}^{-1}\right)$. We also observed more samples above LOD with decreasing $\log \mathrm{K}_{\mathrm{oa}}$ for both indoor and outdoor samples (Figure 2). Deployment of the LDPE was for $24 \mathrm{~h}$, longer deployment times would likely result in more and higher molecular weight PAHs detected.

Figure 3 shows the site-to-site spatial variability for individual PAH concentrations. We observed differences between sites in both detections and concentrations. For instance, some lower molecular weight compounds such as acenaphthene $\left(154.2 \mathrm{~g}-\mathrm{mol}^{-1}\right)$ and fluorene

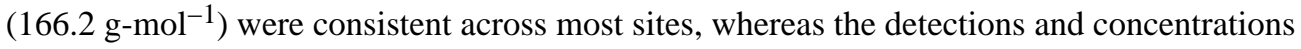
of alkylated, higher molecular weight compounds such as 3,6-dimethylphenanthrene (206.3 $\mathrm{g}$ - $\left.\mathrm{mol}^{-1}\right)$ and 2-methyathracene $\left(192.3 \mathrm{~g}-\mathrm{mol}^{-1}\right)$ varied significantly from site to site. Site F outdoor had the most detects among all outdoor sites, which may be due to its unique position in the center of downtown Eugene near high traffic roads. Despite the site-to-site variability, Figure 3 shows that indoor concentrations are consistently at least equal, if not higher, to outdoor concentrations at each site.

The following results are based on our probabilistic reduction of all 63 PAHs. By implementing the PPCA, which directly accounts for observations below LOD, we were able to reduce the 31 detected PAHs into one representative component, which accounted for $77 \%$ of the variability.

PPCA assumes an underlying normal distribution; therefore, PPCA was performed on logtransformed nmol- $\mathrm{m}^{-3}$ concentrations. The PPCA loadings for the first principal component, are shown in Figure 4A. Every loading was positive except for one, suggesting that PPCA component 1 is positively associated with aggregate PAH concentrations. The additional PPCA components contained a combination of positive and negative loadings and thus lacked the interpretation of PPCA component 1.

Figures $4 \mathrm{~B}$ and $4 \mathrm{C}$ illustrate the impact of wildfire smoke level on the aggregate PAH concentrations for indoor and outdoor environments. The boxplots for each HMS level show that the outdoor PAH concentrations are generally higher with high wildfire smoke levels, while the indoor concentrations are unaffected or inconclusive. A linear model with PPCA score 1 as the dependent variable and HMS a categorical independent variable confirms the results. In the outdoor model, the high HMS level, indicating the most severe wildfire smoke impact, is significant at the 0.10 level $(\mathrm{p}=0.06)$ when compared to the baseline of the lowest HMS level. For the indoor environment, both of the HMS level variables are not significant. Figure 4C, a time series with the HMS levels in the background shows the site-to-site differences in temporal patterns of aggregate PAH concentrations. The differences are confirmed statistically with a site and indoor/outdoor environment interaction linear model. The main effects interaction variable is highly significant at the 0.01 level indicating a strong potential for between site variability of indoor/outdoor concentration differences. Sites A 
and $\mathrm{C}$ indoor aggregate $\mathrm{PAH}$ concentrations (both $\mathrm{p}<1 \mathrm{e}-4$ ) are significantly higher than their corresponding outdoor concentrations and site $\mathrm{F}$ is suggestive $(\mathrm{p}=0.12)$.

This study has limitations to consider. Our assessment of the impact of wildfires on indoor and outdoor gas-phase PAH concentrations was limited by the observed wildfires during the study time range. As shown in figure 4, the study range experienced all levels of the HMS wildfire impact; however, the nearest USEPA air quality index (AQI) monitor never experienced a value above 100 (i.e. the second lowest category). A follow-up study would benefit from more severe wildfire impacts so that our conclusion that indoor gas-phase PAH concentrations are unaffected by wildfires may be assessed during the most severe of conditions. Second, our study sought to address a major gap in the understanding of indoor and outdoor gas-phase pollutants during wildfires; however, we did not quantify particlephase pollutants. Follow-up studies should quantify both the gas- and particle-phase PAHs in indoor and outdoor environments.

Differences in gas-phase PAH exposure from indoor/outdoor location and wildfire events will impact acute and chronic human-health risks. To provide a high-level approximation of potential carcinogenic risks, we apply a traditional risk assessment approach for chemical mixtures known as toxicity equivalency. ${ }^{30}$ This approach scales each chemical's toxicity within the mixtures to a baseline chemical:

$$
B A P_{e q}^{j}=\sum_{i=1}^{i=63} C_{i j} \times T E F_{i}
$$

where $C_{i j}$ is the concentration for PAH $i$ for sample $j, T E F_{i}$ is the toxicity equivalency factor for PAH $i$, and $B A P_{e q}^{j}$ is the resulting benzo[a]pyrene equivalency toxicity for sample $j$. TEF are applied with scaling factors used by Samurova et al. ${ }^{14}$ for the PAHs common to both studies. TEF values used are located in the SI. A limitation of this risk approximation is the difficulty in handling samples below LOD, which we assumed a concentration of zero. We considered using the USEPA Information on the Integrated Risk Assessment (IRIS) relative potency factor (RPF) for PAHs; however, updated values are currently under external review.

The first TEF comparison was between indoor and outdoor environments. Similar to the PPCA analysis, we fit a linear model with log-transformed $B A P_{e q}$ as the dependent variable and the binary indoor/outdoor variable as the independent variable. The $B A P_{e q}$ risk for indoors is significantly higher at the 0.01 level compared to outdoors for all sites together. Next, we compared $B A P_{e q}$ toxicity models for high and low HMS-level days (i.e. high vs low wildfire smoke impact) for both indoor and outdoor environments. The indoor $B A P_{e q}$ toxicity for high HMS days (compared to low HMS days) was not significant at any level, indicating that indoor gas-phase PAH concentrations and risks likely do not differ with wildfire smoke events. The HMS data were observed at all three levels during our study period, but the highest level encompasses a wide range of severe wildfire smoke impacts. Future studies would benefit from assessing indoor gas-phase PAH concentrations during wildfire events in which public health recommendations include all citizens to limit time spent outdoors and to cease outdoor activities, $,{ }^{9}, 10$ which were not made during this study. The outdoor $B A P_{e q}$ toxicity for high HMS days was not significant at the 0.1 level ( $\mathrm{p}=0.11$ ), 
but is nonetheless indicative of potential increased risk from outdoor gas-phase PAHs during high-level wildfire smoke events. A comparable boxplot to Figure $4 \mathrm{~B}$ but for $B A P_{e q}$ toxicity is shown in SI.

Our results show that the household indoor environment may be worse for gas-phase PAH exposure than outdoors. Health policy and recommendations are based entirely on particulate matter exposures and risk, ${ }^{4}$ which omits the potential risk from gas-phase pollutants. The results show that providing human behavioral modification recommendations during wildfire events based on particulate matter may be confounded by the potential risks of gas-phase pollutants. Lastly, these results point toward the need to include gas-phase pollutants such as PAHs in air pollution risk assessment.

\section{Supplementary Material}

Refer to Web version on PubMed Central for supplementary material.

\section{Acknowledgements:}

This work was supported by NIEHS K99 ES029523, NIEHS R33 ES024718, and NIH P42 ES016465. The Pacific Northwest National Laboratory is operated for the U.S. Department of Energy by Battelle Memorial Institute under contract DE-AC05-76RL01830.

\section{References:}

(1). Brenkert-Smith H; Meldrum JR; Champ PA; Barth CM Where You Stand Depends on Where You Sit: Qualitative Inquiry into Notions of Fire Adaptation. Ecol. Soc 2017, $22,7$.

(2). Thomas D; Butry D; Gilbert S; Webb D; Fung J NIST Special Publication 1215. The Costs and Losses of Wildfires A Literature Review; 2017 10.6028/NIST.SP.1215.

(3). Finlay SE; Moffat A; Gazzard R; Murray V Health Impacts of Wildfires. PLoS Curr. 2012, 4 $10.1371 / 4 f 959951 \mathrm{cce} 2 \mathrm{c}$.

(4). Reid CE; Brauer M; Johnston FH; Jerrett M; Balmes JR; Elliott CT Critical Review of Health Impacts of Wildfire Smoke Exposure. Environ. Health Perspect. 2016, 124, 1334-1343. 10.1289/ ehp.1409277. [PubMed: 27082891]

(5). Parry M; Palutikof J; Adger N; Agrawala S; Alcamo J; Cramer W; Murdiyarso D Technical Summary: Climate Change 2007: Impacts, Adaptation and Vulnerability. Contribution of Working Group II to the Fourth Assessment Report of the Intergovernmental Panel on Climate Change. In Cambridge University Press; Parry M, Canziani OF, Palutikof J, Eds.; Cambridge, UK, 2007; pp 23-78.

(6). Littell JS; McKenzie D; Wan HY; Cushman SA Climate Change and Future Wildfire in the Western United States : An Ecological Approach to Nonstationarity. Earth's Futur. 2018, 6 10.1029/2018EF000878.

(7). Williams AP; Abatzoglou JT; Gershunov A; Guzman- J; Bishop DA; Balch JK; Lettenmaier DP Observed Impacts of Anthropogenic Climate Change on Wildfire in California. Earth's Futur. 2019, 7, 892-910. 10.1029/2019EF001210.

(8). Radeloff VC; Helmers DP; Kramer HA; Mockrin MH; Alexandre PM; Bar-Massada A; Butsic V; Hawbaker TJ; Martinuzzi S; Syphard AD; et al. Rapid Growth of the US Wildland-Urban Interface Raises Wildfire Risk. Proc. Natl. Acad. Sci 2018, 115, 3314-3319. 10.1073/ pnas.1718850115. [PubMed: 29531054]

(9). US Environmental Protection Agency; Service, U. F.; California Air Resources Board. Wildfire Smoke: A Guide for Public Health Officials; 2019.

(10). Oregon Health Authority. Wildfires and Smoke https://www.oregon.gov/oha/ph/preparedness/ prepare/pages/prepareforwildfire.aspx (accessed Oct 1, 2019). 
(11). Delgado-saborit JM; Stark C; Harrison RM Carcinogenic Potential, Levels and Sources of Polycyclic Aromatic Hydrocarbon Mixtures in Indoor and Outdoor Environments and Their Implications for Air Quality Standards. Environ. Int 2011, 37, 383-392. 10.1016/ j.envint.2010.10.011. [PubMed: 21146218]

(12). Ramírez N; Cuadras A; Rovira E; Marcé RM; Borrull F Risk Assessment Related to Atmospheric Polycyclic Aromatic Hydrocarbons in Gas and Particle Phases near Industrial Sites. Environ. Health Perspect. 2011, 119, 1110-1116. [PubMed: 21478082]

(13). Liu H-H; Yang H-H; Chou C-D; Lin M-H; Chen H-L Risk Assessment of Gaseous/Particulate Phase PAH Exposure in Foundry Industry. J. Hazard. Mater 2010, 181, 105-111. [PubMed: 20554114]

(14). Samburova V; Zielinska B; Khlystov A Do 16 Polycyclic Aromatic Hydrocarbons Represent PAH Toxicity? Toxics 2017, 5, 29-33. 10.3390/toxics5030017.

(15). USEPA. Report to Congress on Indoor Air Quality, Volume II: Assessment and Control of Indoor Air Pollution. Tech. Rep. EPA/400/1-89/001C 1989.

(16). Klepeis NE; Nelson WC; Ott WR; Robinson JP; Tsang AM; Switzer P; Behar JV; Hern C; Engelmann WH The National Human Activity Pattern Survey (NHAPS): A Resource for Assessing Exposure to Environmental Pollutants. J. Expo. Sci. Environ. Epidemiol 2001, 11, 231-252.

(17). Mitra S; Ray B Patterns and Sources of Polycyclic Aromatic Hydrocarbons and Their Derivatives in Indoor Air. Atmos. Environ 1995, 29, 3345-3356. 10.1016/1352-2310(95)00214-J.

(18). EPA. Wildfires and Indoor Air Quality (IAQ) https://www.epa.gov/indoor-air-quality-iaq/ wildfires-and-indoor-air-quality-iaq? utm_content=\&utm_medium=email\&utm_name=\&utm_source=govdelivery \&utm_term= (accessed Oct 1, 2019).

(19). Paulik LB; Hobbie KA; Rohlman D; Smith BW; Scott RP; Kincl L; Haynes EN; Anderson KA Environmental and Individual PAH Exposures near Rural Natural Gas Extraction. Environ. Pollut 2018, 241, 397-405. [PubMed: 29857308]

(20). Gavin DG; Hallett DJ; Hu FS; Lertzman KP; Prichard J; Brown KJ; Lynch JA; Bartlein P; Peterson DL; Gavinn DG; et al. Forest Fire and Climate Change in Western North America: Insights from Sediment Charcoal Records. 2019, 5, 449-506. 10.1890/060161.

(21). Paulik LB; Donald CE; Smith BW; Tidwell LG; Hobbie KA; Kincl L; Haynes EN; Anderson KA Emissions of Polycyclic Aromatic Hydrocarbons from Natural Gas Extraction into Air. Environ. Sci. Technol 2016, 50, 7921-7929. 10.1021/acs.est.6b02762. [PubMed: 27400263]

(22). Anderson KA; Szelewski MJ; Wilson G; Quimby BD; Hoffman PD Modified Ion Source Triple Quadrupole Mass Spectrometer Gas Chromatograph for Polycyclic Aromatic Hydrocarbon Analyses. J. Chromatogr. A 2015, 1419, 89-98. [PubMed: 26454790]

(23). Huckins JN; Petty JD; Booij K Monitors of Organic Chemicals in the Environment: Semipermeable Membrane Devices; Springer US, 2006.

(24). Khairy MA; Lohmann R Field Validation of Polyethylene Passive Air Samplers for Parent and Alkylated PAHs in Alexandria, Egypt. Environ. Sci. Technol 2012, 46, 3990-3998. [PubMed: 22397460]

(25). Guo Q; Wu W; Massart DL; Boucon C; Jong S De. Feature Selection in Sequential Projection Pursuit. Anal. Chim. Acta 2001, 446, 85-96.

(26). Stacklies W; Redestig H; Scholz M; Walther D; Selbig J PcaMethods - a Bioconductor Package Providing PCA Methods for Incomplete Data. Bioinformatics 2007, 23, 1164-1167. 10.1093/ bioinformatics/btm069. [PubMed: 17344241]

(27). NOAA. Hazard Mapping System Fire and Smoke Product https://www.ospo.noaa.gov/Products/ land/hms.html (accessed Nov 1, 2018).

(28). McNamara D; Stephens G; Ruminski M; Kasheta T The Hazard Mapping System (HMS) NOAA'S Multi-Sensor Fire and Smoke Detection Program Using Environmental Satellites. 13th Conf. Satell. Meteorol. Oceanogr 2004, 22.

(29). USEPA. Estimation Programs Interface Suite for Microsoft Windows, v 4.11. United States Environmental Protection Agency: Washington D.C 2019. 
(30). Nisbet ICT; LaGoy PK Toxic Equivalency Factors (TEFs) for Polycyclic Aromatic Hydrocarbons (PAHs). Regul. Toxicol. Pharmacol 1992, 16, 290-300. [PubMed: 1293646]

(31). OpenStreetMap. Contributors planet.openstreetmap.org (accessed Oct 1, 2019). 

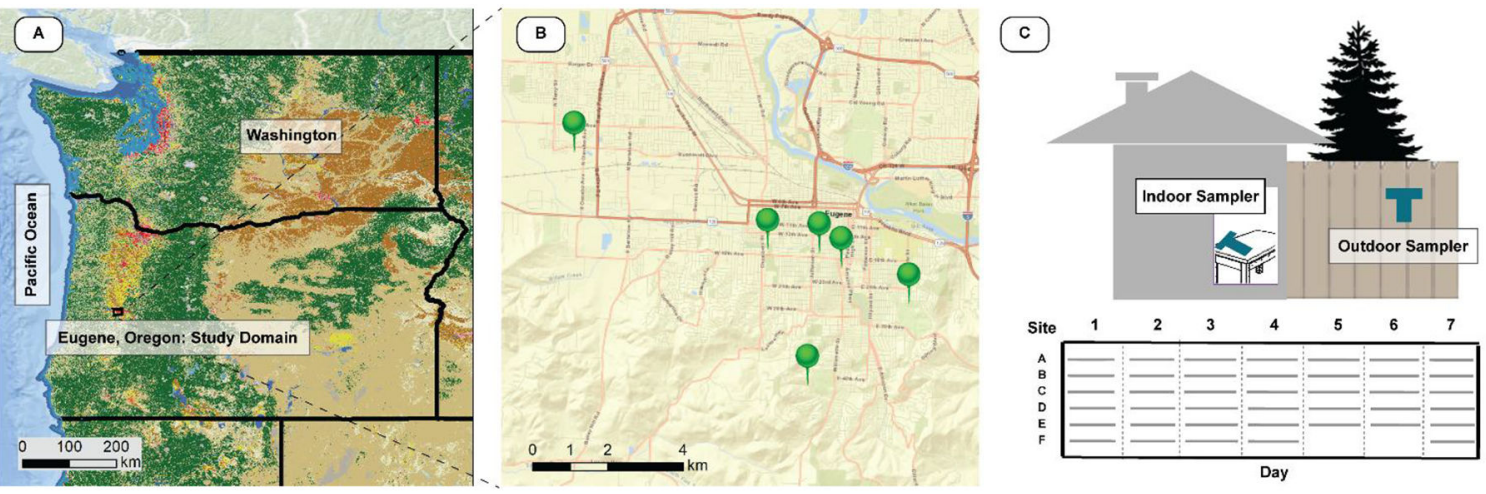

Figure 1. Site domain and study design schematic.

(A) Regional domain of study area. The colors correspond to the land cover classifications in the National Land Cover Database. See https://www.mrlc.gov/data/legends/national-landcover-database-2016-nlcd2016 legend for the color legend. The black box inset shows the local area of the study domain in panel B. (B) Study domain with the six sample locations in large green circles. The circles are intentionally large and randomly shifted a small amount to mask the location. (C) A study design schematic that shows each site included an indoor and an outdoor sampler that were each sampled for seven $24 \mathrm{~h}$ periods. Map layers $(\mathrm{A}, \mathrm{B})$ are based on OpenStreetMaps. ${ }^{31}$ 


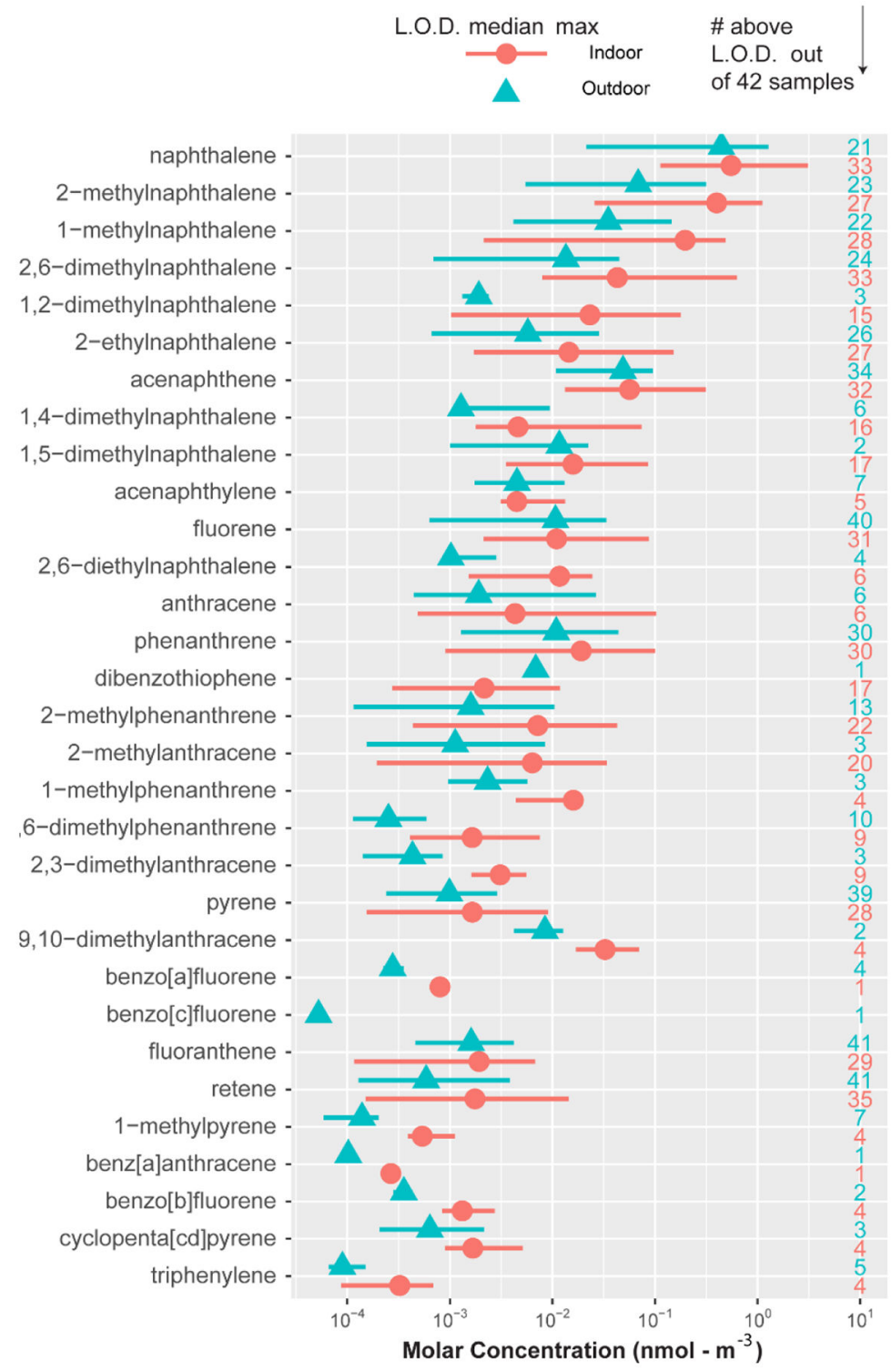

Figure 2. Individual PAH limit of detection (LOD), median, and maximum.

PAH concentrations in indoor and outdoor air environments. Dots are the median concentration. The left end of the line is the limit of detection (LOD), and the right end of the line is the maximum observed value. PAHs with only samples observed below LOD are shown with LOD as a vertical line. The numbers down the right side are the number of samples observed above the LOD, out of a total of 42 for each indoor/outdoor PAH. PAHs are sorted (top-to-bottom) by increasing $\mathrm{Log} \mathrm{K}_{\mathrm{oa}}$ coefficient. PAH by environment with no samples observed above LOD are not shown. 


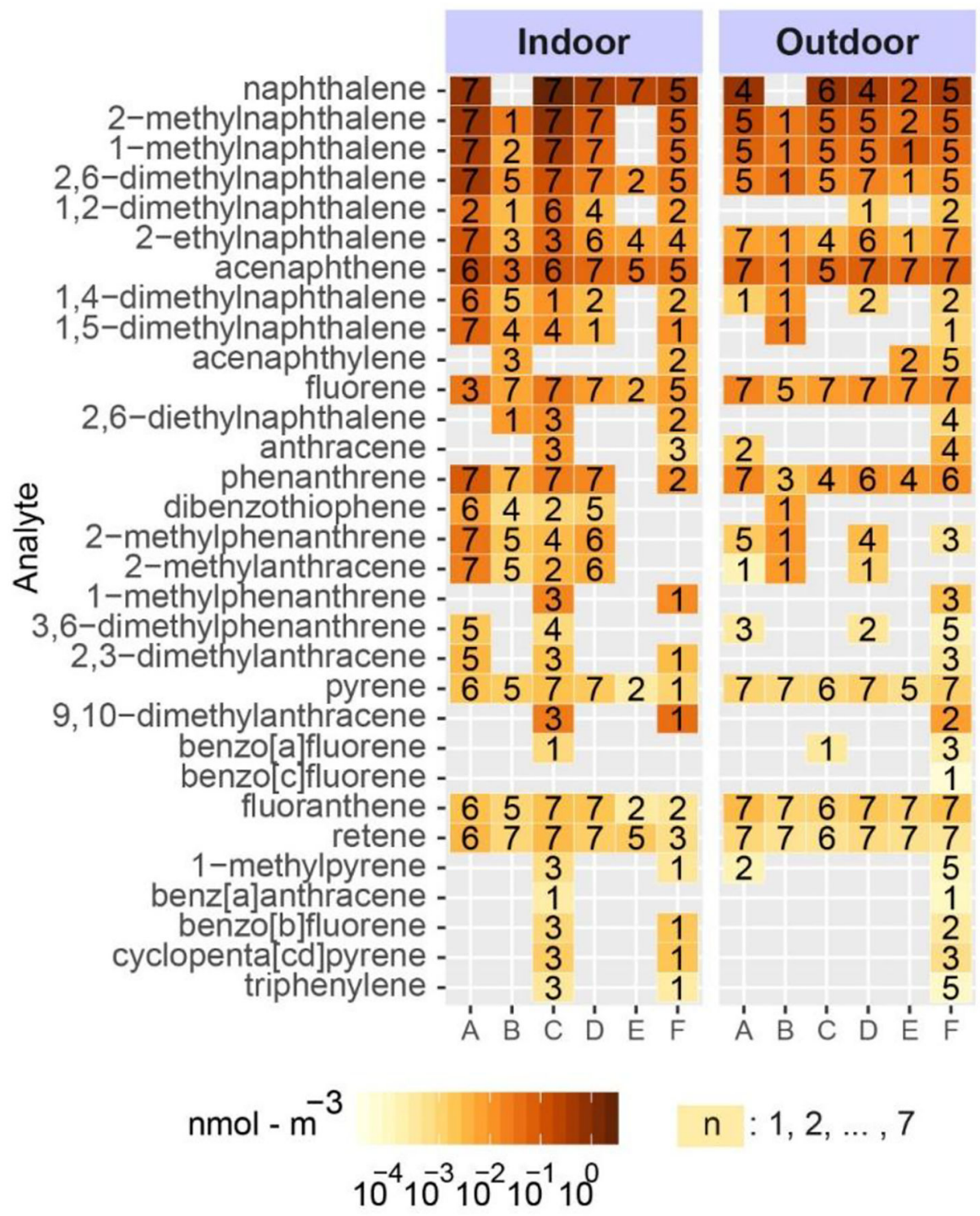

Figure 3. Individual PAH median concentrations by site and indoor/outdoor.

A heatmap of observed individual PAH median concentrations $\left(\mathrm{nmol}-\mathrm{m}^{-3}\right)$, by site (A-F) and by indoor versus outdoor. The number of samples (n) per site per day are shown as a number in the center of each cell (max n possible is 7). PAHs are sorted from top to bottom by increasing $\log \mathrm{K}_{\mathrm{oa}}$. PAHs with all observations below the LOD are not shown. 

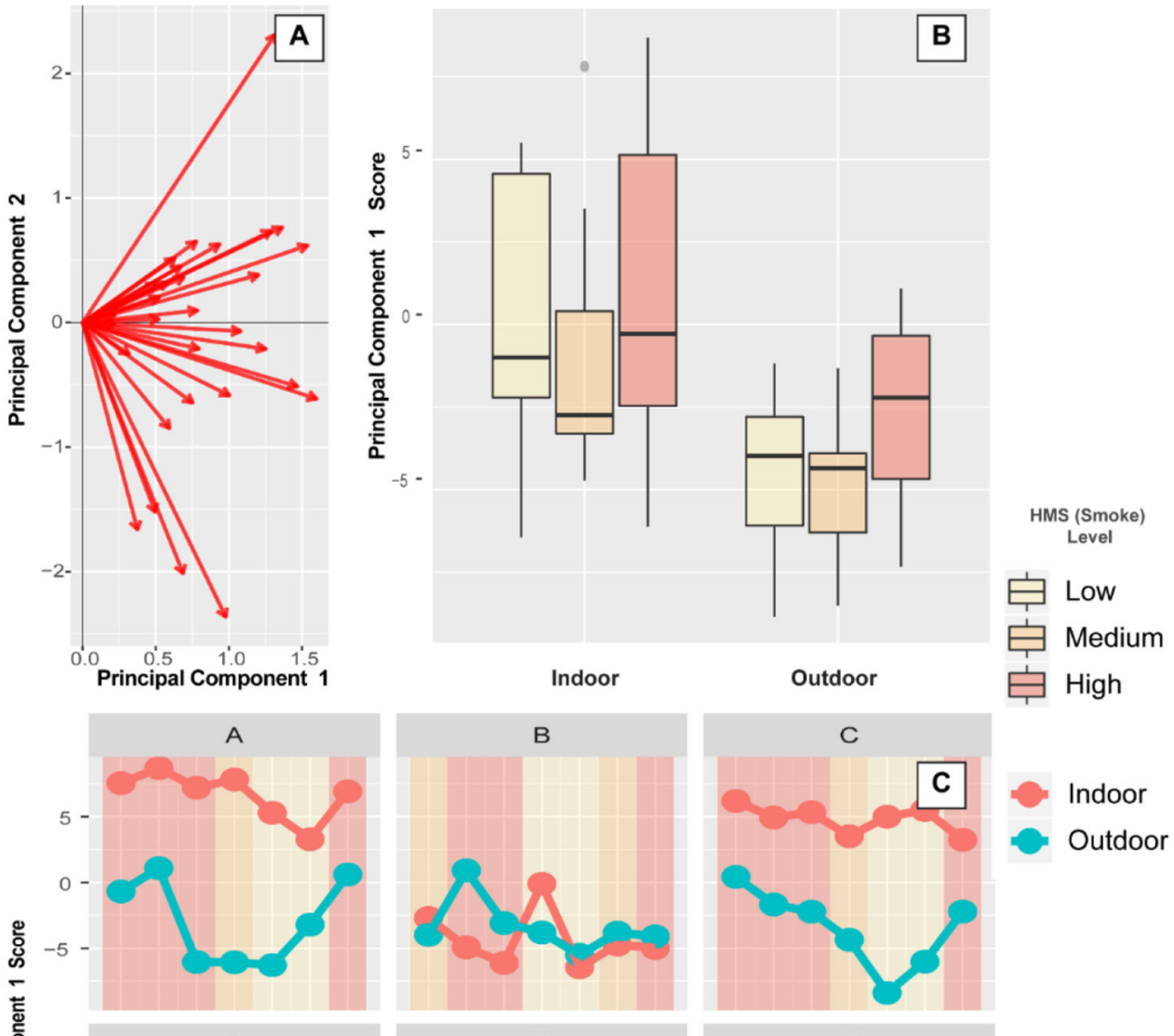

$\mathrm{D}$
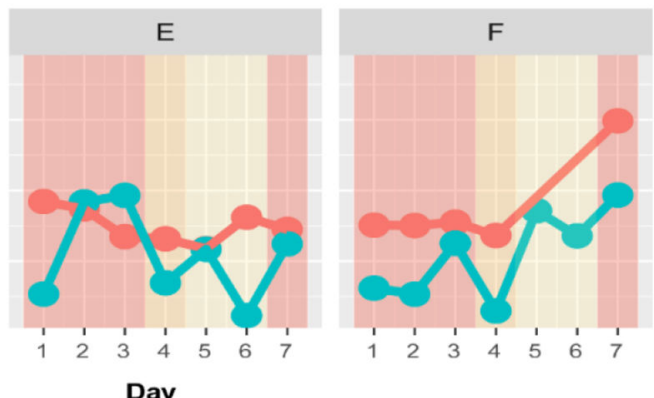

Figure 4. Principal Component Boxplot and Time Series by Indoor/Outdoor Environment and Wildfire Impact.

(A) The probabilistic principal component 1 and 2 loadings. All but 3 loadings for component are positive indicating a positive correlation between the majority of PAHs. This allows for an easy interpretation of principal component score 1 as an aggregate measure of all PAHs. (B) Boxplot of principal component 1 score versus indoor/outdoor and by the 3 levels of wildfire smoke measured in the NOAA Hazard Mapping System (shaded colors). (C) A time series plot of principal component 1 scores by day ( $24 \mathrm{~h}$ integrated samples) and by indoor/outdoor environment. The same colors in B, showing the hazard mapping system level, are displayed as the background color. 